\title{
Therapeutic Index of Herbal Medicine in Pandemic COVID-19: A Review
}

\author{
Neha Tyagi ${ }^{1}$ (D), Santosh Kumar Verma ${ }^{1}$ (D), Ajeet ${ }^{1,2, *}$ (D) \\ 1 Faculty of Pharmaceutical Sciences, Motherhood University, Roorkee, India \\ 2 Department of Pharmaceutical Sciences, Sanskar College of Pharmacy and Research, Ghaziabad, India \\ * Correspondence: ajeet_pharma111@ rediffmail.com (A.);
}

Scopus Author ID 55227575600

Received: 8.08.2021; Revised: 10.10.2021; Accepted: 14.10.2021; Published: 19.12.2021

\begin{abstract}
The study of this review focus on effective herbal medicine against COVID-19. There have been many such plants on which a lot of research has been done earlier, and these have been very good for health as we know that the current situation of the whole world is very serious with the novel COVID-19 virus epidemic. Hence, people consume a lot of herbal medicine to increase their immunity, such as kadha (brewing), and it is also very effective against this viral infection. If we take brewing in the proper dose, research should be done from clinical trials. We have been taking many medicines since old times and have been doing research on them which is Antiviral and useful in different types of infection caused by bacteria, viruses, microbes, etc. The plant's diversity included their chemical constituents, showing the promise of their therapeutic level against the antiviral activity, without any toxicity with plasma concentration. Many plants show effectively against viral infections that are Flavonoids, Glycosides, polyphenols, alkaloids, etc.. Still, any clinical trials on humans do not prove their proper research on them, but the Chinese system of medicine claimed that Traditional Chinese medicine improves the COVID-19 patient. According to this review, we aim to collate data of plants the various large in the quantity of natural active constituents from individual medicinal plant species that may have potential therapeutic efficacy. The continuing development of novel antiviral drugs needs to isolate and synthesize more new active constituents.
\end{abstract}

Keywords: Solanum species; Solasodine; herbal plants; COVID-19 virus.

(C) 2021 by the authors. This article is an open-access article distributed under the terms and conditions of the Creative Commons Attribution (CC BY) license (https://creativecommons.org/licenses/by/4.0/).

\section{Introduction}

At the end of month 2019, new viral pneumonia occurred, and infection cases occurred in Wuhan, China. World Health Organization (WHO) has proven the name of this virus novel COVID-19, this is an infected respiratory pathway, and common symptoms are cough, cold, fever, and sore throat [1]. It has been six months, but there are no clinically approved vaccines for this virus or antiviral drugs available in the market; for the decrease global pandemic disease urgently needed to examine their route of transmission and pathogenic mechanisms in cells and then identify potential drug targets [2].

COVID-19 (SARS-Co) generally affects the respiratory tract system and lungs. They cause pneumonia with complicated symptoms, so the treatment of pneumonia from various therapeutic drugs with research, and these are approved, so there may be a solution somewhere from the therapeutic herbal drugs [3]. China is providing the more effective treatment of viral from the traditional Chinese medicine, that various drugs from china approved by clinical research to these drugs, but there is no clear evidence to stop the coronavirus infection [4]. 
The author can propose that the test with a combination of 5-Fluorouracil and deoxynucleosides on COVID-19 patients should be effective when properly performed on trial because it is tested on animals [5, 6]. According to various studies of infection of COVID-19, there is cytokine's most important role to direct COVID-19, so there are few herbal drugs that show anti-cytokine agents with the formation of the monoclonal antibodies [7].

The Ministry of Health and Family Welfare, Government of India, suggested that a combination of hydroxychloroquine and azithromycin be given to the patients [8], including evaluating the effect of Ayurveda (mixture of herbs) and homeopathy agents on the prevention of COVID-19 [9].

The herbal drugs with combination it treating virus are infection and lungs injury that infected by a viral infection. It also helps to regulate the immune system of the body example: Xuanfei Baidu Tang is a Chinese herbal medicine prevalent to treat viral infections [10].

\section{Holistic Medicine with Faith Healing against SARS-CoV-2}

Extract from china Rheum palmatum L. positive effect against SARS-3CL protease. The SARS-CoV 3CL gene is developed from RNA of the SARS virus through a polymerase chain reaction. A colon bacillus recombinant strain the SARS-CoV 3CL protease. Extract from Rheum palmatum $\mathrm{L}$. and SARS-CoV 3CL protease hatch together. The inhibition rate and IC (50) were calculated according to the absorbance reading. Components from the extract of Chinese palmatum L. show a high level of anti-SARS-CoV 3CL protease activity. The IC(50) value $13.76+/-0.03 \mathrm{microg} / \mathrm{mL}$ with $96 \%$ inhibition rate [11].

The Chalcone derivatives are a group of chemical compounds widely distributed in the plant kingdom. Helichrysetin and isobavachalcone inhibit the mechanism action of MERS CoV 3CLpro. Flavonoids are usefully reducing inhibition of the proteolytic activity of MERS CoV 3CLpro [12].

The crude extract of ToonasinensisRoem leaf includes kaempferol, (+)-catechin, (-)epicatechin, beta-sitosterol, quercetin, quercitrin, rutin, methyl gallate, gallic acid, kaempferold-glucoside, stigmasterol, beta-sitosteryl-glucoside, stigmasterol-glucoside, phytol, and toosendanin. One of those compounds, quercetin, is highly effective and reported antiviral activity against HIV-luc/SARS, Toonasinensis inhibiting SARS-CoV [13].

Small molecules they exist a valuable effect against SARS-CoV; the small isolated molecules are TGG and luteolin; they can inhibit entry of the virus into the host cells with EC50 values of 4.5 and $10.6 \mu \mathrm{M}$, respectively, TGG is an effective component of Gallachinensis and Luteolin Veronica linariifolia Pall [14].

Lianhuaqingwen was used to treat and inhibit influenza and exist broad-spectrum effects of antiviral on influenza viruses with immune regulatory effects, using CPE and plaque reduction assay with in vitro activity, SARS-CoV-2 replication was inhibited in Vero E6 cells, and pro-inflammatory cytokines (TNF-, IL-6, CCL-2/MCP-1, then CXCL-10/IP-10) significantly reduced at the mRNA level. Especially it is effective that is caused by various respiratory virus infections [15].

Corticosteroids are mostly throughout the time of outbreaks of severe acute respiratory syndrome due to (SARS)-CoV and the Middle East respiratory syndrome (MERS)-CoV, it is very extremely admixed with therapeutics and herb doses, but due to the unusual complication, i.e., necrosis, so the Corticosteroids are not any longer want to treat SARS-CoV-2 [16].

Inhibition of SARS-CoV-2 3CLpro by natural products attain from traditional medicines. As the first noncovalent, nonpeptidomimetic inhibitors of SARS-CoV-2 3CLpro, 
baicalin, and baicalein from roots of Scutellariabaicalensis Georgi showed strong antiviral activity in a cell-based system and enzymatic test. A fluorescence resonance energy transfer (FRET) protease assay is applied to measure the proteolytic activity of the recombinant SARSCoV-2 3CLpro on a fluorogenic substrate and, therefore, the product found to be natural and therefore, products and phytochemicals from therapeutics plant as novel inhibitors of SARSCoV-2 3CLpro [17].

Carnosol and Rosmanol investigated against SARS-CoV-2, Coronaviruses contain a positive sense, single-strand RNA genome coding for viral polymerase, RNA synthesis materials, and large non-structural polypeptide, in this case, the Carnosol, Rosmanol, and Arjunglucoside-I.further insights into binding interactions of these compounds with SARSCoV-2 Mpro were analyzed using ligplot (these are images). These therapeutic molecules are highly hydrogen bond donors and acceptors [18].

Viniferin and myricitrin show the active activity on the site mechanism of SARS-CoV2; these molecules show antiviral activity. These molecules have an affinity to bind against all targets, and it is a docking study[19].

There are Crocin, Digitoxigenin, and $\beta$-Eudesmol to evaluate inhibitors against the coronavirus depending on the energy types of interaction allying these molecules and study of protein. They inhibit the main protease of SARS-CoV-2 through docking studies [20].

SARS-CoV-2 within the world number the third deadliest virus from the coronavirus family. Consistent with the WHO analysis, up to March 11, 2020, there are about 118,319 laboratory-confirmed COVID-19 cases in more than 100 countries worldwide. Although Natural herbal medicine is an effective therapy, the results of this study suggest that natural herbal medicine is effective to play a task in promoting recovery through controlling fever symptoms and capacity for the absorption of lung lesions. In recent research, various results indicate that we should also pay more attention to the possible curative effect of herbal medicines on the gastrointestinal symptoms of COVID-19 [21].

In this review, according to Scutellariae radix, Artemisiaeannuae Herbal, and Belamcandaerhizoma mixture, one cluster. These three herbs have a heat-clearing effect and are effectively used together in the herbal formulation. There was no efficacy evidence of the herbal formulae for the treatment of pediatric COVID-19, but due to various research, the herb Glycyrrhizae Radix BelamcandaeRhizoma, both have antiviral and anti-inflammatory efficacy and are highly used in various new herbal medicine whenever the herb Armeniacae Semen is used for respiratory disease and highly used as the severity of disease in children [22].

Herbal medicine in the treatment of SARS was revealed by recent researches positive. Furthermore, the Chinese herbal effective medicine continuations for the treatment of COVID19 pneumonia [23].

According to this review, the author reveals about Jinhua Qinggan granules. Jinhua Qinggan granules are good formulae as Antiviral and respiratory systems. It's definite study affects the treatment of COVID-19 patients, but it is not regularly evaluated for efficacy and safety. There is various high in quality evidence of Jinhua Qinggan granules for COVID-19 [24].

Table 1. Antiviral chemical constituents.

\begin{tabular}{l|l|l|l|l}
$\begin{array}{l}\text { Chemical } \\
\text { constituents }\end{array}$ & Biological source & Family & Uses & Ref \\
\hline Helichrysetin & $\begin{array}{l}\text { Helichrysumodoratiss } \\
\text { ium }\end{array}$ & Sunflower famiy & $\begin{array}{l}\text { Antiviral } \\
\text { Neuritogenic effects }\end{array}$ & {$[25]$} \\
\hline Carnosol & R. officinalis & Lamiaceae & Antiviral & {$[26]$}
\end{tabular}




\begin{tabular}{|c|c|c|c|c|}
\hline $\begin{array}{l}\text { Chemical } \\
\text { constituents }\end{array}$ & Biological source & Family & Uses & Ref \\
\hline Rosmol & R. officinalis & Lamiaceae & $\begin{array}{l}\text { Antivirals such as antioxidant, anti- } \\
\text { inflammatory, analgesic }\end{array}$ & [27] \\
\hline Arjunglucoside I & Terminalia chebula & Combretaceae & Antiviral, Diabetes etc. & {$[28]$} \\
\hline Luteolin flavonoid & Reseda Lutolea & Flavonoid family & $\begin{array}{l}\text { Antioxidant, antiviral, and heart- } \\
\text { protective }\end{array}$ & [29] \\
\hline Theaflavin & Camellia sinensis & Theaceae & $\begin{array}{l}\text { Antiviral against SARS-CoV-2 by } \\
\text { Computer modeling. }\end{array}$ & {$[30]$} \\
\hline $\begin{array}{l}\text { Tetra-O-galloyl- } \beta \text { - } \\
\text { D-glucose }\end{array}$ & Gallachinensis & Anacardeaceae & Preventing entry viral with bind $\mathbf{S} 2$ bind & {$[31]$} \\
\hline $\begin{array}{l}\alpha \text {-pinene, } \quad \delta-3- \\
\text { carene, } \alpha \text {-cedrol }\end{array}$ & Thujaorientalis & Cupressaceae & Inhibit the viral replication & [32] \\
\hline Caffeic acid & Sambucus formosana & Adoxaceae & Inhibit the viral by cell docking & [33] \\
\hline Tryptanthrin & Strobilanthescusia leaf & Acanthaceae & Blocking RNA genome & {$[34]$} \\
\hline
\end{tabular}

A mixture of the Indigowoad Root (Isatis Indigotica), (Corydalis Bungeana)Bunge Corydalis, Mongolian Dandelion (Taraxacum Mongolicum), Scutellaria Amoena (Scutellaria Baicalensis). These therapeutic agents have strong antiviral and antibacterial activity and are widely used in the treatment of acute bronchitis and respiration diseases.

The researcher evaluated that mixture efficiency against SARS-CoV-2 via in vitro and in vivo studies because these therapeutic drugs target database of mixture formulation could perhaps have the potential effect on the asthma disorder $(p=2.41 \mathrm{E}-03)$, chronic obstructive pulmonary disease $(\mathrm{p}=2.45 \mathrm{E}-03)$, which is correlative to COVID-19 which provide the discernment for the treatment of the COVID-19. It needs to constantly exhibit robust antiSARS-CoV-2 with powerful final results in vitro and in vivo, which can be clinically used for the prevention and treatment of pneumonia caused by SARS-CoV-2 infection $[35,36]$.

Further, studies about herbal drugs provide more platforms for the treatment or prevention of COVID-19; tobacco is good for the treatment of COVID-19 because the plant constituents that are NICTABA lectin which is a strong antiviral agent [37].

According to various research on plants, they contain a functional group that Particularly hydroxyl (-OH) group, which is effective because it's a chemical reaction for deactivating the lively additives of the virus through an esterification system. As one case looks at, the usage of one of the herbal resources, for instance, liquorice (Glycyrrhiza glabra) which include components of glycyrrhizin, glycyrrhetic acid, liquiritin, and isoliquiritin with useful active molecules that may be used to neutralize the activeness of COVID-19 and it may be further used as an antiviral drug [38].

Herbal plants widely studied and further research ultimate for treating COVID-19 include an extract of glycyrrhiza, ephedra, bitter almond, gypsum, amomum, reed root, and trichosanthes. Herbal medicine primarily functions to lower the heat and remove toxicity to exit heat sense from the lungs to relieve cough and further increase the immunity system of the body $[39,40]$.

Theaflavin is a potent constituent that is a potential inhibitor against the RNAdependent RNA polymerase of SARS-CoV-2 [41].

Probably the chance to treat coronavirus in the human body through they include griffithsin, lycorine, and polyphenolicsscutellarein, Isobavachalcone is constituted of silvestrol, tryptanthrin, and the lectins quercetin, myricetin, caffeic acid, and psoralidin. There is no need to emphasize that certain quantities of these substances could be hazardous to humans and lead to complications. Hence, each therapeutic chemical's safe and therapeutic levels must be determined through in vitro and in vivo testing [42, 43]. 
These medicines are derived from earlier studies on SARS, MERS, and other novel influenza viruses that could be employed as COVID-19 treatment drugs. Further research and addition computer molecular docking show that these active constituents have good binding proper ability and effect to COVID-19 virus and host targets [44, 45].

Chloroquine and hydroxychloroquine inhibit glycosylation of host receptors because viruses enter into these host cells with inhibition endosomal acidification, and as well as proteolytic processing, and also inhibition of autophagy and breakdown of the damaged cells before they cause an issue in host cells [46]. They promote cytokine production and regulate immunity. These drugs also help the absorption of pneumonia in COVID-19 patients. Further, Chloroquine and Hydroxychloroquine have shown anti-SARS-CoV-2 and effective results should have been found both in vivo and in vitro researches [47].

Andrographispaniculata plant extract isolates the Andrographolide, and it is the main component of this plant; it is highly recommended for antiviral activity [48]. In Docking key targets with andrographolide, it binds spike protein ACE2, 3CLpro, and PLpro, which shows that it has a good antiviral against SARS-CoV-2, with low cytotoxicity [49].

Sesquiterpene compound extracted Patchouli alcohol that shows the binding effect of PA and Rdrp in docking study on SARS-CoV-2. It shows an antiviral effect [50].

Many studies from various research and reviews this plant reported that this inhibits Antiviral activities. Glycyrrhizae Radix et Rhizome also has a good anti-inflammatory activity suitable for treating inflammatory lung conditions in COVID-19 [51].

It was also revealed in many researches and review articles that synthetic chemical moieties are found effective against COVID-19 [52, 53], but after completing this review, we can suppose that herbal medicines and drugs are far better effective against it.

\section{Conclusions}

Naturally occurring phytochemicals provide a valuable chemical modification of structures directed by the computer-based docking simulations method, which may also enhance their potency activity in research. Some of the most important key compounds that show the treatment of coronavirus in humans Further research process is developing safe, effective anti-coronavirus therapeutic agents from naturally occurring compounds.

\section{Funding}

This research received no external funding.

\section{Acknowledgments}

I would like to express my special thanks of gratitude to my Principal Dr. Santosh Kumar Verma, and teacher Dr. Ajeet, who helped me do a lot of research/review, and I came to know about so many new things. I am thankful to them.

\section{Conflicts of Interest}

The authors declare no conflict of interest. 


\section{References}

1. Jin, Y.-H.; Cai, L.; Cheng, Z.-S.; Cheng, H.; Deng, T.; Fan, Y.-P.; Fang, C.; Huang, D.; Huang, L.-Q.; Huang, Q.; Han, Y.; Hu, B.; Hu, F.; Li, B.-H.; Li, Y.-R.; Liang, K.; Lin, L.-K.; Luo, L.-S.; Ma, J.; Ma, L.-L.; Peng, Z.-Y.; Pan, Y.-B.; Pan, Z.-Y.; Ren, X.-Q.; Sun, H.-M.; Wang, Y.; Wang, Y.-Y.; Weng, H.; Wei, C.-J.; Wu, D.-F.; Xia, J.; Xiong, Y.; Xu, H.-B.; Yao, X.-M.; Yuan, Y.-F.; Ye, T.-S.; Zhang, X.-C.; Zhang, Y.-W.; Zhang, Y.-G.; Zhang, H.-M.; Zhao, Y.; Zhao, M.-J.; Zi, H.; Zeng, X.-T.; Wang, Y.-Y.; Wang, X.-H.; Management, F.T.Z.H.O.W.U.N.C.; Research Team, E.-B.M.C.O.C.I.E. Promotive Association for, M.; Health, C. A rapid advice guideline for the diagnosis and treatment of 2019 novel coronavirus (2019-nCoV) infected pneumonia (standard version). Military Medical Research 2020, 7, https://doi.org/10.1186/s40779-020-0233-6.

2. Li, J.-Y.; You, Z.; Wang, Q.; Zhou, Z.-J.; Qiu, Y.; Luo, R.; Ge, X.-Y. The epidemic of 2019-novelcoronavirus (2019-nCoV) pneumonia and insights for emerging infectious diseases in the future. Microbes and Infection 2020, 22, 80-85, https://doi.org/10.1016/j.micinf.2020.02.002.

3. Wang, Z.; Chen, X.; Lu, Y.; Chen, F.; Zhang, W. Clinical characteristics and therapeutic procedure for four cases with 2019 novel coronavirus pneumonia receiving combined Chinese and Western medicine treatment. BioScience Trends 2020, 14, 64-68, https://doi.org/10.5582/bst.2020.01030.

4. Du, H.-Z.; Hou, X.-Y.; Miao, Y.-H.; Huang, B.-S.; Liu, D.-H. Traditional Chinese Medicine: an effective treatment for 2019 novel coronavirus pneumonia (NCP). Chinese Journal of Natural Medicines 2020, 18, 206-210, https://doi.org/10.1016/S1875-5364(20)30022-4.

5. Ahmad, S.I. 5-Fluorouracil in combination with deoxyribonucleosides and deoxyribose as possible therapeutic options for the Coronavirus, COVID-19 infection. Medical hypotheses 2020, 142.

6. Al-Tawfiq, J.A.; Al-Homoud, A.H.; Memish, Z.A. Remdesivir as a possible therapeutic option for the COVID-19. Travel medicine and infectious disease 2020, 34,

7. Kotwani, A.; Gandra, S. Potential pharmacological agents for COVID-19. Indian journal of public health 2020, 64, 112-116.

8. Revised Guidelines on Clinical Management of COVID-19. Ministry of Health and FamilyWelfare, Government of India. Available from: https:/www.mohfw.gov.in/pdf/RevisedNationalClin icalManagementGuidelineforCOVID1931032020.pdf

9. Clinical Trials Registry - India. ICMR - National Institute of Medical Sciences. Available from http://ctri.nic.in/Clinicaltrials/advancesearchmain.php.

10. Wang, Y.; Li, X.; Zhang, J.-H.; Xue, R.; Qian, J.-Y.; Zhang, X.-H.; Zhang, H.; Liu, Q.-Q.; Fan, X.-H.; Cheng, Y.-Y. Mechanism of Xuanfei Baidu Tang in treatment of COVID-19 based on network pharmacology. Zhongguo Zhong yao za zhi= Zhongguo Zhongyao Zazhi= China Journal of Chinese Materia Medica 2020, 45, 2249-2256, https://doi.org/10.19540/j.cnki.cjcmm.20200325.401.

11. Luo, W.; Su, X.; Gong, S.; Qin, Y.; Liu, W.; Li, J.; Yu, H.; Xu, Q. Anti-SARS coronavirus 3C-like protease effects of Rheum palmatum L. extracts. Bioscience trends 2009, 3, 1204-6.

12. Phan, C.-W.; Sabaratnam, V.; Yong, W.-K.; Abd Malek, S.N. The role of chalcones: helichrysetin, xanthohumol, and flavokawin-C in promoting neurite outgrowth in PC12 Adh cells. Natural Product Research 2018, 32, 1229-1233, https://doi.org/10.1080/14786419.2017.1331226.

13. Chen, C.-J.; Michaelis, M.; Hsu, H.-K.; Tsai, C.-C.; Yang, K.D.; Wu, Y.-C.; Cinatl Jr, J.; Doerr, H.W. Toona sinensis Roem tender leaf extract inhibits SARS coronavirus replication. Journal of ethnopharmacology 2008, 120, 108-111.

14. Yi, L.; Li, Z.; Yuan, K.; Qu, X.; Chen, J.; Wang, G.; Zhang, H.; Luo, H.; Zhu, L.; Jiang, P.; Chen, L.; Shen, Y.; Luo, M.; Zuo, G.; Hu, J.; Duan, D.; Nie, Y.; Shi, X.; Wang, W.; Han, Y.; Li, T.; Liu, Y.; Ding, M.; Deng, $\mathrm{H}$; $\mathrm{Xu}, \mathrm{X}$. Small Molecules Blocking the Entry of Severe Acute Respiratory Syndrome Coronavirus into Host Cells. Journal of Virology 2004, 78, 11334-11339, https://doi.org/10.1128/JVI.78.20.1133411339.2004.

15. Runfeng, L.; Yunlong, H.; Jicheng, H.; Weiqi, P.; Qinhai, M.; Yongxia, S.; Chufang, L.; Jin, Z.; Zhenhua, J.; Haiming, J.; Kui, Z.; Shuxiang, H.; Jun, D.; Xiaobo, L.; Xiaotao, H.; Lin, W.; Nanshan, Z.; Zifeng, Y. Lianhuaqingwen exerts antiviral and anti-inflammatory activity against novel coronavirus (SARS-CoV-2). Pharmacological Research 2020, 156, https://doi.org/10.1016/j.phrs.2020.104761.

16. Russell, C.D.; Millar, J.E.; Baillie, J.K. Clinical evidence does not support corticosteroid treatment for 2019nCoV lung injury. The Lancet 2020, 395, 473-475, https://doi.org/10.1016/S0140-6736(20)30317-2.

17. Su, H.; Yao, S.; Zhao, W.; Li, M.; Liu, J.; Shang, W.; Xie, H.; Ke, C.; Gao, M.; Yu, K.; Liu, H.; Shen, J.; Tang, W.; Zhang, L.; Zuo, J.; Jiang, H.; Bai, F.; Wu, Y.; Ye, Y.; Xu, Y. Discovery of baicalin and baicalein as novel, natural product inhibitors of SARS-CoV-2 3CL protease \&lt;em\&gt;in vitro\&lt;/em\&gt. bioRxiv 2020, https://doi.org/10.1101/2020.04.13.038687.

18. Kundu, D.; Selvaraj, C.; Singh, S.K.; Dubey, V.K. Identification of new anti-nCoV drug chemical compounds from Indian spices exploiting SARS-CoV-2 main protease as target. Journal of Biomolecular Structure and Dynamics 2021, 39, 3428-3434, https://doi.org/10.1080/07391102.2020.1763202.

19. Joshi, R.S.; Jagdale, S.S.; Bansode, S.B.; Shankar, S.S.; Tellis, M.B.; Pandya, V.K.; Chugh, A.; Giri, A.P.; Kulkarni, M.J. Discovery of potential multi-target-directed ligands by targeting host-specific SARS-CoV-2 
structurally conserved main protease. Journal of Biomolecular Structure and Dynamics 2021, 39, 3099-3114, https://doi.org/10.1080/07391102.2020.1760137.

20. Aanouz, I.; Belhassan, A.; El-Khatabi, K.; Lakhlifi, T.; El-ldrissi, M.; Bouachrine, M. Moroccan Medicinal plants as inhibitors against SARS-CoV-2 main protease: Computational investigations. Journal of

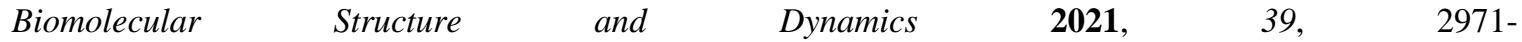
2979, https://doi.org/10.1080/07391102.2020.1758790.

21. Zhang, H.-T.; Huang, M.-X.; Liu, X.; Zheng, X.-C.; Li, X.-H.; Chen, G.-Q.; Xia, J.-Y.; Hong, Z.-S. Evaluation of the Adjuvant Efficacy of Natural Herbal Medicine on COVID-19: A Retrospective Matched Case-Control Study. The American Journal of Chinese Medicine 2020, 48, 779-792, https://doi.org/10.1142/S0192415X20500391.

22. Ang, L.; Lee, H.W.; Kim, A.; Lee, J.A.; Zhang, J.; Lee, M.S. Herbal medicine for treatment of children diagnosed with COVID-19: A review of guidelines. Complementary Therapies in Clinical Practice 2020, 39, https://doi.org/10.1016/j.ctcp.2020.101174.

23. Li, Y.; Liu, X.; Guo, L.; Li, J.; Zhong, D.; Zhang, Y.; Clarke, M.; Jin, R. Traditional Chinese herbal medicine for treating novel coronavirus (COVID-19) pneumonia: protocol for a systematic review and meta-analysis. Systematic Reviews 2020, 9, https://doi.org/10.1186/s13643-020-01343-4.

24. Chen, H.; Song, Y.-P.; Gao, K.; Zhao, L.-T.; Ma, L. Efficacy and safety of Jinhua Qinggan granules for coronavirus disease 2019 (COVID-19): A protocol of a systematic review and meta-analysis. Medicine 2020, 99, https://doi.org/10.1097/MD.0000000000020612.

25. Phan, C.-W.; Sabaratnam, V.; Yong, W.-K.; Abd Malek, S.N. The role of chalcones: helichrysetin, xanthohumol, and flavokawin-C in promoting neurite outgrowth in PC12 Adh cells. Natural Product Research 2018, 32, 1229-1233, https://doi.org/10.1080/14786419.2017.1331226.

26. Hobtemariam, S. The Therapeutic Potential of Rosemary (Rosmarinus officinalis) Diterpenes for Alzheimer's Disease. Evidence-Based Complementary and Alternative Medicine 2016, 2016, https://doi.org/10.1155/2016/2680409.

27. Andrade, J.M.; Faustino, C.; Garcia, C.; Ladeiras, D.; Reis, C.P.; Rijo, P. Rosmarinus officinalis L.: an update review of its phytochemistry and biological activity. Future Science OA 2018, 4, https://doi.org/10.4155/fsoa-2017-0124.

28. Jokar, A.; Masoomi, F.; Sadeghpour, O.; Nassiri-Toosi, M.; Hamedi, S. Potential therapeutic applications for Terminalia chebula in Iranian traditional medicine. Journal of Traditional Chinese Medicine 2016, 36, 250254, https://doi.org/10.1016/S0254-6272(16)30035-8.

29. Manzoor, M.F.; Ahmad, N.; Ahmed, Z.; Siddique, R.; Zeng, X.-A.; Rahaman, A.; Muhammad Aadil, R.; Wahab, A. Novel extraction techniques and pharmaceutical activities of luteolin and its derivatives. Journal of Food Biochemistry 2019, 43, https://doi.org/10.1111/jfbc.12974.

30. Lung, J.; Lin, Y.S.; Yang, Y.H.; Chou, Y.L.; Shu, L.H.; Cheng, Y.C.; Liu, H.T.; Wu, C.Y. The potential chemical structure of anti-SARS-CoV-2 RNA-dependent RNA polymerase. Journal of medical virology 2020, 92, 693-697.

31. Yi, L.; Li, Z.; Yuan, K.; Qu, X.; Chen, J.; Wang, G.; Zhang, H.; Luo, H.; Zhu, L.; Jiang, P. Small molecules blocking the entry of severe acute respiratory syndrome coronavirus into host cells. Journal of virology 2004, 78, 11334-11339.

32. Loizzo, M.R.; Saab, A.M.; Tundis, R.; Statti, G.A.; Menichini, F.; Lampronti, I.; Gambari, R.; Cinatl, J.; Doerr, H.W. Phytochemical analysis and in vitro antiviral activities of the essential oils of seven Lebanon species. Chemistry \& biodiversity 2008, 5, 461-470.

33. Weng, J.-R.; Lin, C.-S.; Lai, H.-C.; Lin, Y.-P.; Wang, C.-Y.; Tsai, Y.-C.; Wu, K.-C.; Huang, S.-H.; Lin, C.W. Antiviral activity of Sambucus FormosanaNakai ethanol extract and related phenolic acid constituents against human coronavirus NL63. Virus research 2019, 273.

34. Tsai, Y.C.; Lee, C.L.; Yen, H.R. Antiviral action of tryptanthrin isolated from Strobilanthescusia leaf against human coronavirus NL63. Biomolecules 2020, 10.

35. Deng, W.; Xu, Y.; Kong, Q.; Xue, J.; Yu, P.; Liu, J.; Lv, Q.; Li, F.; Wei, Q.; Bao, L. Therapeutic efficacy of Pudilan Xiaoyan Oral Liquid (PDL) for COVID-19 in vitro and in vivo. Signal Transduction and Targeted Therapy 2020, 5, https://doi.org/10.1038/s41392-020-0176-0.

36. Feng, L.; Yang, N.; Li, C.; Tian, G.; Wang, J.; Dong, Z.-B.; Jia, X.-B.; Di, L.-Q. Pudilan xiaoyan oral liquid alleviates LPS-induced respiratory injury through decreasing nitroxidative stress and blocking TLR4 activation along with NF-KB phosphorylation in mice. Journal of Ethnopharmacology 2018, 214, 292-300, https://doi.org/10.1016/j.jep.2017.07.009.

37. Yonesi, M.; Rezazadeh, A. Plants as a Prospective Source of Natural Anti-viral Compounds and Oral Vaccines Against COVID-19 Coronavirus. 2020.

38. Chowdhury, M.A.; Shahid, M.A.; Kashem, M.A. Scope of natural plant extract to deactivate COVID-19. Preprint 2020, 3, https://doi.org/10.21203/rs.3.rs-19240/v1.

39. Wan, S.; Xiang, Y.; Fang, W.; Zheng, Y.; Li, B.; Hu, Y.; Lang, C.; Huang, D.; Sun, Q.; Xiong, Y.; Huang, X.; Lv, J.; Luo, Y.; Shen, L.; Yang, H.; Huang, G.; Yang, R. Clinical features and treatment of COVID-19 patients in northeast Chongqing. Journal of Medical Virology 2020, 92, 797-806, https://doi.org/10.1002/jmv.25783. 
40. Chen, R.-C.; Tang, X.-P.; Tan, S.-Y.; Liang, B.-L.; Wan, Z.-Y.; Fang, J.-Q.; Zhong, N. Treatment of severe acute respiratory syndrome with glucosteroids: the Guangzhou experience. Chest 2006, 129, 1441-1452.

41. Zhang, D.-H.; Wu, K.-L.; Zhang, X.; Deng, S.-Q.; Peng, B. In silico screening of Chinese herbal medicines with the potential to directly inhibit 2019 novel coronavirus. Journal of integrative medicine 2020, 18, 152158, https://doi.org/10.1016/j.joim.2020.02.005.

42. Mani, J.S.; Johnson, J.B.; Steel, J.C.; Broszczak, D.A.; Neilsen, P.M.; Walsh, K.B.; Naiker, M. Natural product-derived phytochemicals as potential agents against coronaviruses: A review. Virus Research 2020, 284, https://doi.org/10.1016/j.virusres.2020.197989.

43. Chu, D.K.W.; Pan, Y.; Cheng, S.M.S.; Hui, K.P.Y.; Krishnan, P.; Liu, Y.; Ng, D.Y.M.; Wan, C.K.C.; Yang, P.; Wang, Q.; Peiris, M.; Poon, L.L.M. Molecular Diagnosis of a Novel Coronavirus (2019-nCoV) Causing an Outbreak of Pneumonia. Clinical Chemistry 2020, 66, 549-555, https://doi.org/10.1093/clinchem/hvaa029.

44. Huang, F.; Li, Y.; Leung, E.L.-H.; Liu, X.; Liu, K.; Wang, Q.; Lan, Y.; Li, X.; Yu, H.; Cui, L.; Luo, H.; Luo, L. A review of therapeutic agents and Chinese herbal medicines against SARS-COV-2 (COVID-19). Pharmacological Research 2020, 158, https://doi.org/10.1016/j.phrs.2020.104929.

45. Zumla, A.; Chan, J.F.W.; Azhar, E.I.; Hui, D.S.C.; Yuen, K.-Y. Coronaviruses — drug discovery and therapeutic options. Nature Reviews Drug Discovery 2016, 15, 327-347, https://doi.org/10.1038/nrd.2015.37.

46. Gao, J.; Tian, Z.; Yang, X. Breakthrough: Chloroquine phosphate has shown apparent efficacy in treatment of COVID-19 associated pneumonia in clinical studies. BioScience Trends 2020, 14, 72-73, https://doi.org/10.5582/bst.2020.01047.

47. Yao, X.; Ye, F.; Zhang, M.; Cui, C.; Huang, B.; Niu, P.; Liu, X.; Zhao, L.; Dong, E.; Song, C.; Zhan, S.; Lu, R.; Li, H.; Tan, W.; Liu, D. In Vitro Antiviral Activity and Projection of Optimized Dosing Design of Hydroxychloroquine for the Treatment of Severe Acute Respiratory Syndrome Coronavirus 2 (SARS-CoV2). Clinical Infectious Diseases 2020, 71, 732-739, https://doi.org/10.1093/cid/ciaa237.

48. Uttekar, M.M.; Das, T.; Pawar, R.S.; Bhandari, B.; Menon, V.; Nutan; Gupta, S.K.; Bhat, S.V. Anti-HIV activity of semisynthetic derivatives of andrographolide and computational study of HIV-1 gp120 protein binding. European Journal of Medicinal Chemistry 2012, 56, 368-374, https://doi.org/10.1016/j.ejmech.2012.07.030.

49. Enmozhi, S.K.; Raja, K.; Sebastine, I.; Joseph, J. Andrographolide as a potential inhibitor of SARS-CoV-2 main protease: an in silico approach. Journal of Biomolecular Structure and Dynamics 2021, 39, 3092-3098, https://doi.org/10.1080/07391102.2020.1760136.

50. Yu, Y.; Zhang, Y.; Wang, S.; Liu, W.; Hao, C.; Wang, W. Inhibition effects of patchouli alcohol against influenza a virus through targeting cellular PI3K/Akt and ERK/MAPK signaling pathways. Virology Journal 2019, 16, https://doi.org/10.1186/s12985-019-1266-x.

51. Ang, L.; Lee, H.W.; Choi, J.Y.; Zhang, J.; Lee, M.S. Herbal medicine and pattern identification for treating COVID-19: a rapid review of guidelines. Integrative Medicine Research 2020, 9 , https://doi.org/10.1016/j.imr.2020.100407.

52. Ajeet; Aggarwal, B.; Kumar Verma, S.; Singh, A. Docking Analysis of 07 Anti-HCV Drugs with COVID19 Main Protease PDB ID: 6LU7. American Journal of Pharmacological Sciences 2021, 8, 21-25.

53. Ajeet, A.; Aggarwal, B.; Verma, S. Chemical Moieties/Peptide Mediated Options for Combating Corona Virus: A Review. American Journal of Pharmacological Sciences 2020 8, 7-8, https://doi.org/10.12691/ajps$8-1-2$. 